\title{
HAMP - the microwave package on the High Altitude and LOng range research aircraft (HALO)
}

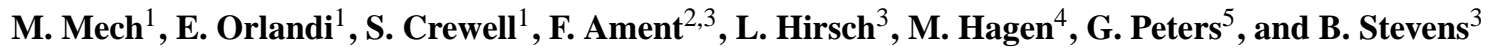 \\ ${ }^{1}$ Institute for Geophysics and Meteorology, University of Cologne, Cologne, Germany \\ ${ }^{2}$ University of Hamburg, Hamburg, Germany \\ ${ }^{3}$ Max Planck Institute for Meteorology, Hamburg, Germany \\ ${ }^{4}$ DLR Institute for Physics of the Atmosphere, Oberpfaffenhofen, Germany \\ ${ }^{5}$ Metek GmbH, Elmshorn, Germany \\ Correspondence to: M. Mech (mech@meteo.uni-koeln.de)
}

Received: 17 February 2014 - Published in Atmos. Meas. Tech. Discuss.: 8 May 2014

Revised: 31 October 2014 - Accepted: 16 November 2014 - Published: 20 December 2014

\begin{abstract}
An advanced package of microwave remote sensing instrumentation has been developed for the operation on the new German High Altitude LOng range research aircraft (HALO). The HALO Microwave Package, HAMP, consists of two nadir-looking instruments: a cloud radar at $36 \mathrm{GHz}$ and a suite of passive microwave radiometers with 26 frequencies in different bands between 22.24 and $183.31 \pm 12.5 \mathrm{GHz}$. We present a description of HAMP's instrumentation together with an illustration of its potential. To demonstrate this potential, synthetic measurements for the implemented passive microwave frequencies and the cloud radar based on cloud-resolving and radiative transfer model calculations were performed. These illustrate the advantage of HAMP's chosen frequency coverage, which allows for improved detection of hydrometeors both via the emission and scattering of radiation. Regression algorithms compare HAMP retrieval with standard satellite instruments from polar orbiters and show its advantages particularly for the lower atmosphere with a root-mean-square error reduced by 5 and $15 \%$ for temperature and humidity, respectively. HAMP's main advantage is the high spatial resolution of about $1 \mathrm{~km}$, which is illustrated by first measurements from test flights. Together these qualities make it an exciting tool for gaining a better understanding of cloud processes, testing retrieval algorithms, defining future satellite instrument specifications, and validating platforms after they have been placed in orbit.
\end{abstract}

\section{Introduction}

Water in all its phases is, from the perspective of Earth's climate, the most important atmospheric constituent (Stevens and Bony, 2013a), but it is still poorly measured and poorly understood. Limitations in our understanding of water also have a profound influence on climate modeling and climate prediction (Stevens and Bony, 2013b) and demand new experimental approaches. Airborne remote sensing measurements are a useful tool to investigate cloud processes. Due to the finer resolution, the better sensitivity, and the higher flexibility of aircraft observations compared to satellite observations, the atmosphere can be studied in more detail. Furthermore, such instruments play an important role in calibrating satellites and validating geophysical retrieval algorithms.

Microwave instruments are well suited to observing clouds and precipitation because condensed phases of water are semitransparent in this spectral region. Since the first launch of the Special Sensor Microwave Imager (SSM/I) instrument in 1987, passive microwave satellite instruments have been the backbone for deriving climatologies of cloud liquid water path (LWP) and precipitation (O'Dell et al., 2008; Andersson et al., 2010) and the most reliable source for estimating precipitation trends (Allan et al., 2010). Over the radiatively cold ocean, the observed radiances at frequencies below roughly $50 \mathrm{GHz}$ can be directly related to precipitation via the thermal emission of liquid water. However, at these low frequencies (long wavelengths), the spatial resolution of $\mathrm{SSM} / \mathrm{I}$ is roughly $50 \mathrm{~km}$ and the inhomogeneous beam fill- 
ing causes a significant source of uncertainty (von Bremen et al., 2002). Better resolution is achieved at higher frequency channels operating at window frequencies. However, scattering by ice particles increases with frequency and the relation between hydrometeor content and measured brightness temperatures is rather complex. Use of microwave emissions is more challenging over land because of the high and variable surface emission $(\epsilon \approx 0.6-0.95)$. In this case the scattering signal can be used to improve estimates of precipitation by assuming a relation between surface precipitation and the ice aloft (Kidd and Huffman, 2011). Active microwave observation by radar can provide vertically resolved profiles of hydrometeor backscatter, though the direct conversion to water content is complicated by the dependence on particle size and shape as well as attenuation effects.

To overcome the limitations of the individual techniques and better constrain the profiles of hydrometeors in the atmosphere, a combination of multispectral microwave radiometers with active microwave instruments (Bauer et al., 2001; Skofronick-Jackson et al., 2003) is pursued. The strong benefit of this synergy is most prominently illustrated by the success of the Tropical Rainfall Measuring Mission (TRMM), which has delivered a 15-year precipitation climatology (Wang et al., 2013) by combining the TRMM Microwave Imager (TMI) and the Precipitation Radar (PR). However, TRMM is confined to tropical oceans and, due to the Kuband radar detection limit of $+18 \mathrm{dBZ}$ (NASDA, 1999) and large footprint, misses light precipitation (Berg et al., 2010; Nuijens et al., 2009). This leads to substantial uncertainties when estimating the contribution of precipitation to the global energy budget (Stephens et al., 2012). Though the Wband radar on CloudSat (Stephens et al., 2002) has a better sensitivity $(-27 \mathrm{dBZ})$ and a smaller footprint, a significant portion of the clouds are not detected. The Global Precipitation Mission (GPM; Hou et al., 2013), with its core satellite launched in February 2014, will address the problem of temporal sampling by using a constellation of research and operational microwave sensors. However, the radar sensitivity of $+12 \mathrm{dBZ}$ will not allow for study of clouds or light precipitation.

During the last decades, a number of active and passive microwave instruments have been developed for airborne operation (see Pelon et al., 2013; Wendisch et al., 2013, for an overview), with some of them specifically designed for the validation of satellite data, e.g., the National Polar-Orbiting Operational Environmental Satellite System (NPOESS) Aircraft Sounding Testbed-Microwave (NAST-M; Blackwell et al., 2001) or the Conical Scanning Millimeter-Wave Imaging Radiometer (CoSMIR; Wang et al., 2007) for the Special Sensor Microwave Imager/Sounder (SSMIS). Specific satellite validation campaigns - e.g., for AMSR precipitation validation at Wakasa Bay (Lobl et al., 2007; Wang et al., 2008), for SSMIS, or for CloudSat (Barker et al., 2008) - as well as a large number of campaigns dedicated to studying processes (Geerts et al., 2000; Evans et al., 2005), were performed on different aircraft. Another example is the Compact Scanning Submillimeter-wave Imaging Radiometer (CoSSIR; Toon et al., 2010) for ice cloud observations operated during the Tropical Composition, Cloud and Climate Coupling (TC4) campaign. Airborne measurements are often limited by the aircraft's available power and therefore the synergy of active and passive sensors on one aircraft with similar view is seldom realized on a single airborne platform. An exception which proves the rule is the combination of the dual frequency High-Altitude Imaging Wind and Rain Airborne Profiler (HIWRAP; Li et al., 2008) and the HighAltitude Monolithic Microwave Integrated Circuit (MMIC) Sounding Radiometer (HAMSR) flown on the unmanned high-altitude, long-endurance Global Hawk to investigate hurricane genesis and intensification (Braun et al., 2013). HIWRAP is a dual-frequency $(\mathrm{Ka}(35 \mathrm{GHz})$ and $\mathrm{Ku}$ band $(14 \mathrm{GHz})$ ) radar similar to the one flown by GPM, but with a detection limit of about $0 \mathrm{dBZ}$ it is not sensitive enough to capture clouds and light precipitation. HAMSR is a crosstrack scanning microwave sounder (Brown et al., 2011) with 25 channels in three spectral bands connected with the 60 and $119 \mathrm{GHz}$ oxygen and the $183 \mathrm{GHz}$ water vapor line that are of particular interest for future satellite missions, e.g., MetOp Second Generation (MetOp-SG). During the Tropical Cloud Systems and Processes experiment (TCSP; Halverson et al., 2007), HAMSR was operated on the ER-2 (Earth Resources2) aircraft together with the Cloud Radar System (CRS; Li et al., 2003), a $94 \mathrm{GHz}$ radar.

Here we present the HALO Microwave Package (HAMP). HAMP provides an advanced suite of microwave cloud remote sensing instruments for operation onboard the new German High-Altitude LOng-range research aircraft (HALO) (Ziereis and Gläßer, 2006). The package consists of microwave radiometers with 26 channels that in addition to HAMSR frequencies also includes the low-frequency channels along the $22 \mathrm{GHz}$ water vapor line ( $\mathrm{K}$ band) for better estimation of rain and cloud liquid water, together with the thermodynamic environment (temperature and humidity profiles). In addition to its unique frequency combination, HAMP also includes a high-sensitivity cloud radar at $35.5 \mathrm{GHz}$ ( $-38 \mathrm{dBZ}$ at $5 \mathrm{~km}$ and $1 \mathrm{~s}$ avg.), making it a versatile tool for studying both clouds and precipitation in different regions of the world that are difficult to assess with ground-based instrumentation. The first HALO mission with HAMP onboard was the Next-generation Aircraft Remote sensing for VALidation studies (NARVAL) campaign in December 2013 and January 2014. In that campaign, dedicated flights were performed over the tropical Atlantic to study trade wind cumulus and over the North Atlantic across polar lows to investigate the uncertainty of precipitation retrievals reported by Klepp et al. (2003).

This paper introduces the installation of the microwave package on HALO along with its instrument characteristics. Furthermore, it illustrates the potential of the observations by presenting a retrieval study based on synthetic observations, 
which have been created with a cloud-resolving model and detailed radiative transfer modeling covering a wide variety of cloud and precipitation regimes. In Sect. 5, first measurements taken during a scientific test flight over Germany are presented.

\section{System description}

\subsection{Aircraft and installation of the instruments}

The new German research aircraft HALO is a Gulfstream G550 - a commercial business jet - modified to include atmospheric and geophysical sensors. Its operating range is more than $12500 \mathrm{~km}$ with an airspeed of Mach 0.8 or 10 flight hours, and a ceiling of about $15 \mathrm{~km}$. HALO can carry a payload of almost $3 \mathrm{t}$ and has $55 \mathrm{~kW}$ of available power. These features make it possible to survey the troposphere, and in places the lower stratosphere, on planetary scales with much finer resolution and with more powerful instrumentation than feasible on spaceborne platforms.

For remote sensing purposes the Max Planck Institute for Meteorology and the University of Hamburg together with the German Aerospace Center and the University of Cologne have developed an advanced suite of microwave instrumentation. These instruments are subdivided into three boxes for the passive radiometers plus the active radar component. In addition, the German Aerospace Center operates a multiwavelength water vapor differential absorption lidar (WALES; Wirth et al., 2009) and a dropsonde system onboard HALO (Hock and Franklin, 1999).

The boxes containing the passive microwave radiometers are mounted in a belly pod (Fig. 1) secured to the underside of the aircraft's forward fuselage. The belly pod is made of multilayered carbon fiber material and has dimensions of $700 \mathrm{~cm} \times 120 \mathrm{~cm} \times 90 \mathrm{~cm}$ (length $\times$ width $\times$ height) and is connected to the main fuselage by cables to provide power and access to control and data acquisition systems. Flight testing shows that the belly pod exerts no significant influence on flight altitude, speed, and distance, although there is a slight reduction in range. All instruments are configured to be nadir pointing. Because the aircraft cruises at a pitch angle of between 0 and $4^{\circ}$, the instrument viewing angle varies in this range on level legs.

\subsection{Cloud radar}

The radar MIRA-36 (Melchionna et al., 2008), owned by University of Hamburg and manufactured by METEK, is a monostatic, pulsed, magnetron, Ka band, Doppler radar that operates at $35.5 \mathrm{GHz}$. The advantage of the Ka band as compared to the more common $94 \mathrm{GHz}$, or $\mathrm{W}$ band, is its reduced attenuation in the presence of condensate. Using this frequency is possible because the HALO aircraft and its belly pod is sufficiently large to accommodate the relatively large antenna required at this frequency. The radar has

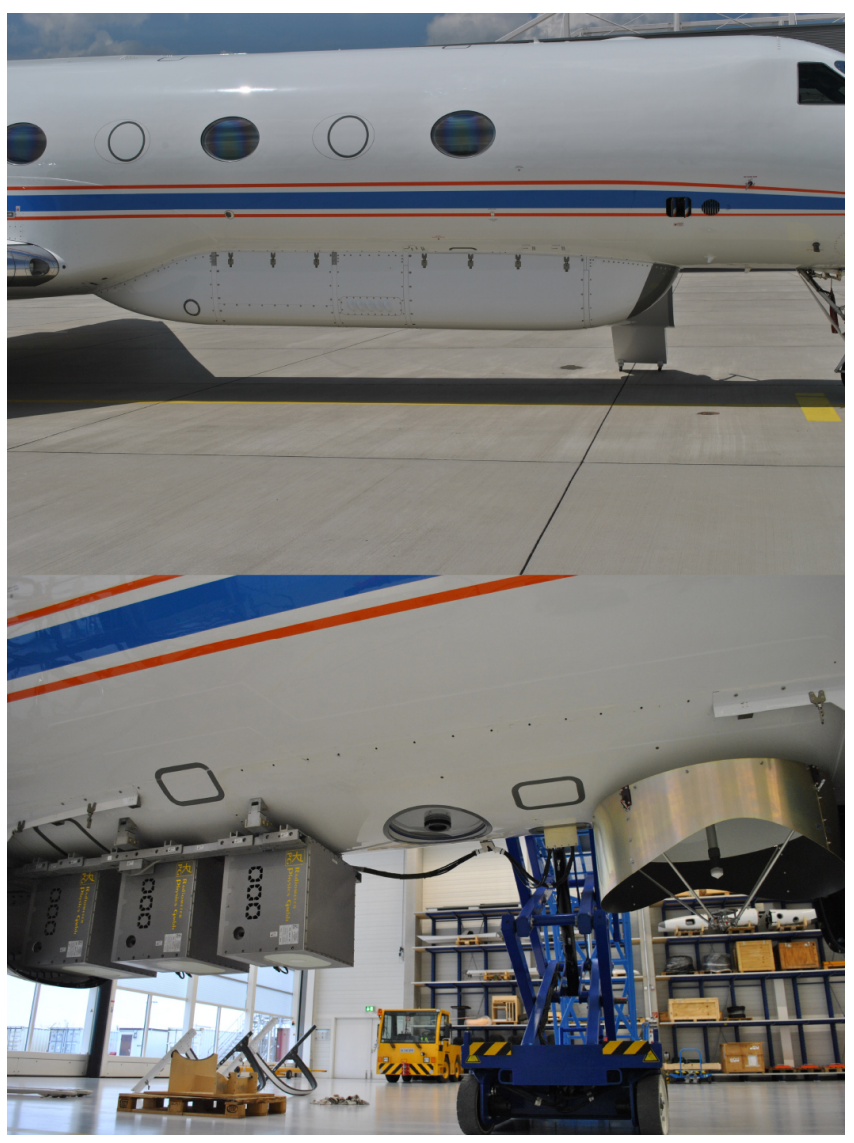

Figure 1. Top: closed belly pod mounted on HALO. Bottom: remote sensing instruments underneath the body of HALO (from left to right: HALO-G, HALO-KV, and HALO-WF module; lidar window; and cloud radar MIRA-36 antenna).

two receivers to provide a co- and cross-polarization channel. The output parameters are the radar reflectivity $(Z)$, the Doppler spectra, the Doppler velocity or line of sight velocity of targets $(V)$, the spectral width, and the linear depolarization ratio (LDR). An advantage of the monostatic, pulsed magnetron is that it captures strong gradients in the reflectivity precisely. This is especially important to avoid problems with ground reflection in nadir-looking instruments.

The radar is operated using a $1 \mathrm{~m}$ diameter Cassegrain antenna mounted in the belly pod connected to the radar electronics in the cabin. Here, a custom flange had to be designed to support the antenna and accommodate the feed-through for the wave guide. The radome window in the belly pod underwent intensive tests to estimate the optimum thickness of the radome material to minimize the two-way attenuation to less than $2.0 \mathrm{~dB}$. The key specifications of the cloud radar are summarized in Table 1. The radar's transmitter and receiver are initially calibrated using external sources and internal references sources are continually used to achieve a permanent calibration of the system. 
Table 1. Specifications of the cloud radar MIRA-36 as a component of HAMP.

\begin{tabular}{|c|c|}
\hline Parameter & MIRA-36 \\
\hline Frequency & $35.563 \mathrm{GHz}$ \\
\hline Peak power & $30 \mathrm{~kW}$ \\
\hline Pulse length ${ }^{\mathrm{a}}$ & $200 \mathrm{~ns}$ \\
\hline Pulse repetition $^{\mathrm{a}}$ & $5 \mathrm{kHz}$ \\
\hline Integration time, coherent ${ }^{\mathrm{a}}$ & $0.05 \mathrm{~s}$ \\
\hline Integration time, incoherent ${ }^{\mathrm{a}}$ & $1 \mathrm{~s}$ \\
\hline Range resolution ${ }^{\mathrm{a}}$ & $30 \mathrm{~m}$ \\
\hline Beam width & $0.6^{\circ}$ \\
\hline Footprint & $130 \mathrm{~m}^{\mathrm{b}}$ \\
\hline $\begin{array}{l}\text { Sensitivity ground-based } \\
\text { operation }\end{array}$ & $-48 \mathrm{dBZ}^{\mathrm{c}}$ \\
\hline Expected sensitivity & \\
\hline airborne operation & $-38 \mathrm{dBZ}^{\mathrm{c}},-30 \mathrm{dBZ}{ }^{\mathrm{d}}$ \\
\hline Minimum detectable LDR & $-40 \mathrm{~dB}$ \\
\hline Parameters & $Z, V$, spectral width, LDR \\
\hline
\end{tabular}

${ }^{\text {a }}$ Adjustable. ${ }^{\text {b }}$ At $13 \mathrm{~km}$ range. ${ }^{\mathrm{c}}$ At $5 \mathrm{~km}$ with $1 \mathrm{~s}$ avg. ${ }^{\mathrm{d}}$ At $13 \mathrm{~km}$ with $1 \mathrm{~s} \mathrm{avg.}$

Compared to ground-based cloud radar, two additional effects have a major influence on the retrieved Doppler velocities. The first effect is the contribution of the aircraft speed to the mean Doppler velocity in the case that the radar is not pointing exactly nadir (see more detailed discussion in Lee et al., 1994). With a typical aircraft speed of $210 \mathrm{~m} \mathrm{~s}^{-1}$ and a forward pitch angle of $2^{\circ}$, this offset accounts for $-7.33 \mathrm{~m} \mathrm{~s}^{-1}$ (negative means towards the aircraft). In the case of vertical shear of the horizontal wind between the measurement height and the height of the aircraft, an additional offset by the projection of the horizontal wind vector on the flight direction has to be considered. The second effect of the aircraft motion is the broadening of the Doppler spectrum due to the beam width. Even in the case of an antenna pointing exactly nadir, part of the radar beam is pointing forward and backward, thus seeing an offset in Doppler velocity. In total this results in a broadening of the velocity distribution in the radar measurement volume.

Figure 2 illustrates the effects of aircraft geometry (speed $210 \mathrm{~m} \mathrm{~s}^{-1}$ and pitch angle $2^{\circ}$ ) for a monodisperse distribution with zero vertical motion. In addition to the velocity shift of about $7 \mathrm{~m} \mathrm{~s}^{-1}$, the spectrum is also broadened by $2 \mathrm{~m} \mathrm{~s}^{-1}$. Although the total power is conserved, the spectral line density is thus reduced by approximately $13 \mathrm{~dB}$. While the power peak of the original monodisperse spectrum might be above the noise level, the power peak of the broadened spectrum could be below the noise level. This has an effect on the ability to detect clouds with low reflectivity. Software algorithms may be able to diminish this reduction in sensitivity to 8 $9 \mathrm{~dB}$. The resulting sensitivity for airborne operation has to be estimated from in-flight data sets, but is expected to be in the range of $-38 \mathrm{dBZ}$. For rain events the loss in peak power is hardly evident as shown for a Marshall-Palmer size distribution with a rain rate of $5 \mathrm{~mm} \mathrm{~h}^{-1}$ (Fig. 2). The mean Doppler velocity changes from 7.21 to $-0.12 \mathrm{~m} \mathrm{~s}^{-1}$, and the spectral width from 1.40 to $1.53 \mathrm{~m} \mathrm{~s}^{-1}$.

The ability of the radar to detect clouds and precipitation close to the Earth surface depends on the range bin resolution, the length of the transmitted pulse, and the sharpness of the pulse edges. Side lobes of the radar beam can produce an artificial signal below the surface because they reach the surface later than the main lobe. In the case of strong rainfall, this can also result from multiple scattering.

\subsection{Passive microwave radiometers}

\subsubsection{Radiometer systems}

The HAMP microwave radiometers are owned by the Max Planck Institute and were custom-manufactured for HALO by Radiometer Physics GmbH (RPG). They are separated into three nadir-pointing modules mounted in the belly pod underneath HALO (see Fig. 1). Each of the modules has a weight of approximately $95 \mathrm{~kg}$ and dimensions of $46 \mathrm{~cm} \times$ $56 \mathrm{~cm} \times 54 \mathrm{~cm}$.

The first module contains two independent packages with parallel antenna axis for the $\mathrm{K}$ and $\mathrm{V}$ bands (hereafter HALO-KV). Both units are direct detection filter bank receivers similar in design to the one within the ground-based Humidity and Temperature Profiler (HATPRO; Rose et al., 2005) that is used at several locations worldwide for automatic thermodynamic profiling and measurements of the liquid water path (LWP). The second module consists of two independent receiver packages (hereafter HALO-11990): one direct detection radiometer at a window channel at $90 \mathrm{GHz}$ and one heterodyne receiver in double-sideband mode with four channels along the $118.75 \mathrm{GHz} \mathrm{O}$ line from \pm 1.4 to $\pm 8.5 \mathrm{GHz}$. The third module (hereafter HALO-183) contains a single heterodyne receiver providing seven channels along the $183.31 \mathrm{GHz} \mathrm{H}_{2} \mathrm{O}$ line $( \pm 0.6$ to $\pm 12.5 \mathrm{GHz}$, double sideband). The radiometers view the atmosphere through existing apertures in the belly pod, which are covered by window material with low microwave attenuation.

The accuracy of the measured brightness temperatures $\left(T_{\mathrm{B}}\right)$ is determined by the quality of the calibration and by the noise component. During flight the radiometer channels are continuously calibrated using two reference loads: one is at ambient temperature, i.e., around $40^{\circ} \mathrm{C}$, corresponding to the stabilized receiver box temperature, and the second is generated by a noise diode whose temperature varies between 1000 and $1500 \mathrm{~K}$ for the different frequency channels. The ambient load is realized by a terminated Dicke switch, with the exception of the HALO-183 module, where instead of waveguide technology the receiver is terminated by quasi-optical switching to an internal ambient temperature target (T. Keating Ltd sub-millimeter plastic absorber). The noise diode signal is frequently injected via a directional coupler and used for gain calibration, while the receiver noise temperature $\left(T_{\mathrm{r}}\right)$ 

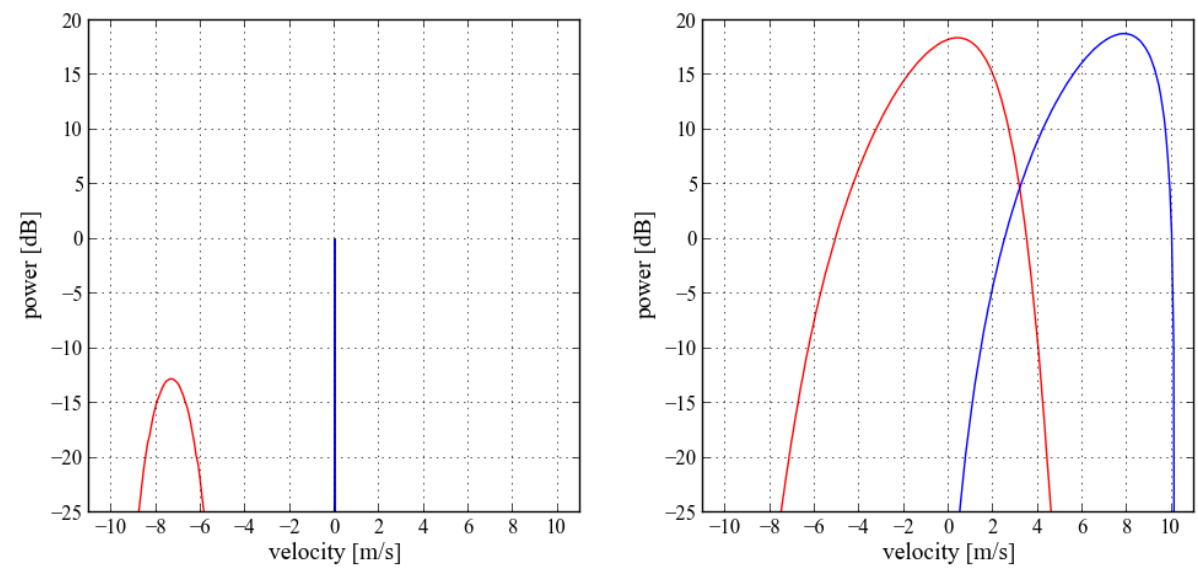

Figure 2. Original (blue) and aircraft-affected (red) Doppler spectra for monodisperse cloud (left) and typical rain particle distribution (right). Aircraft speed is $210 \mathrm{~m} \mathrm{~s}^{-1}$ and pitch angle $2^{\circ}$. Marshall-Palmer size distribution with rain rate of $5 \mathrm{~mm} \mathrm{~h}^{-1}$ is assumed.

is adjusted by viewing the ambient target every $60 \mathrm{~s}$. By using a magnetically operated Dicke switch, the interruption in observation time is negligible, while for the HALO-183 a few seconds are lost. For the K- and V-band channels this technique has been proven to fulfill the demanding requirements for deep-space stations (Norenberg et al., 2008; Tortora et al., 2013).

The noise diode temperatures and any losses in the optical path, i.e., from antenna windows or Dicke switches, that are not taken into account by the two-load calibration are determined before/after each flight by placing two external loads (liquid nitrogen and ambient temperature) each about $1 \mathrm{~m}$ diameter below the aircraft fuselage.

All HAMP modules are thermally stabilized with an accuracy of $<0.05 \mathrm{~K}$ over the whole operating temperature range $\left(-70\right.$ to $\left.+35^{\circ} \mathrm{C}\right)$ in order to reduce drifts. The frequency bandwidth is $230 \mathrm{MHz}$ for all $\mathrm{KV}$ channels and up to $2 \mathrm{GHz}$ for window frequencies where no spectral features occur. $T_{\mathrm{r}}$ is typically $450 \mathrm{~K}$ ( $\mathrm{K}$ band), $650 \mathrm{~K}$ ( $\mathrm{V}$ band), $1000 \mathrm{~K}$ ( $\mathrm{W}$ band), $2000 \mathrm{~K}$ (F band), and $2300 \mathrm{~K}$ (G band). Together with an integration time of $1 \mathrm{~s}$ used for all channels, this leads to a noise-equivalent delta temperature $(\mathrm{NeDT})$ ranging from $0.1 \mathrm{~K}$ for HALO-KV to $0.6 \mathrm{~K}$ for HALO-183 (Table 2).

With the exception of HALO-183, which uses an off-axis parabolic mirror, the antennas are realized by a corrugated feed horn/aperture lens combination in all HAMP modules. Due to the different wavelengths, the beam width measured as full width at half maximum (FWHM) varies between $5.0^{\circ}$ for HALO-KV and $2.7^{\circ}$ for HALO-183 (Table 2). With these beam widths, for an integration time of $1 \mathrm{~s}$ and a maximum operating Mach number of 0.885 , the resolution at ground for a ceiling height of $13 \mathrm{~km}$ is between 1.4 and $0.9 \mathrm{~km}$ in the along-flight direction and between 1.1 and $0.6 \mathrm{~km}$ in the across-flight direction.

The sideband response has been measured to be identical in both sidebands. It is important to note that the interpreta- tion of the double-sideband signals requires radiative transfer simulations to take both sidebands into account.

\subsubsection{Frequency selection}

The frequencies for the three modules of passive microwave radiometers (see Table 2) were selected to cover the main spectral signatures in the microwave spectral range similarly to currently operated (Advanced Microwave Sounding Unit (AMSU)-A and -B, SSM/I, Microwave Humidity Sounder (MHS); Kidder et al., 2000) and forthcoming satellite instruments like the GPM Microwave Imager (GMI; Bidwell et al., 2005) or the Microwave Imager (MWI) on MetOp-SG, covering attenuation and window regions of the microwave spectrum.

Channels around absorption lines or line complexes are used for temperature or humidity profiling throughout the troposphere and lower stratosphere. The altitude sensitivity of the HAMP sounding channels is illustrated by the clearsky weighting functions in Fig. 3. These are calculated for the US 1976 Standard Atmosphere and a ceiling height of $13 \mathrm{~km}$. The channels along the two $\mathrm{H}_{2} \mathrm{O}$ lines, i.e., $22.24 \mathrm{GHz}$ ( $\mathrm{K}$ band) and $183.31 \mathrm{GHz}$ ( $\mathrm{G}$ band), allow for the retrieval of atmospheric water vapor profiles and its integrated value (IWV). In contrast to AMSU-B and MHS, which have three channels around the $183.31 \mathrm{GHz}$ line, HAMP utilizes more channels further away from the line. With a maximum distance of $12.5 \mathrm{GHz}$, the outer channels are less affected by water vapor (Fig. 3) and can be assumed to be window channels. In comparison to satellite instruments, i.e., AMSU-A, fewer channels close to the $60 \mathrm{GHz} \mathrm{O}_{2}$ absorption complex (V band) are used as these are aimed at stratospheric temperature profiling. Nevertheless, the two innermost V-band channels show a high sensitivity to the temperature close to the aircraft. The four frequency channels along the $118.75 \mathrm{GHz}$ $\mathrm{O}_{2}$ line ( $\mathrm{F}$ band) are chosen to provide similar response to temperature as the corresponding V-band channels. 
Table 2. HAMP passive bands with their noise-equivalent delta temperature (NeDT), absolute accuracy (Acc.), beam width (full width at half maximum, FWHM), their main use in retrieving atmospheric variables, and corresponding satellite instruments. Upcoming missions (instruments) are shown in bold letters.

\begin{tabular}{|c|c|c|c|c|c|}
\hline Band & Frequencies $[\mathrm{GHz}]$ & NeDT $[K] / A c c .[K]$ & FWHM & Application & Satellite \\
\hline $\begin{array}{l}\mathrm{K} \\
\mathrm{H}_{2} \mathrm{O}\end{array}$ & $\begin{array}{l}22.24,23.04 \\
23.84,25.44 \\
26.24,27.84 \\
31.40\end{array}$ & $0.1 / 0.5$ & $5.0^{\circ}$ & $\begin{array}{l}\text { humidity profile, } \\
\text { integrated water vapor, } \\
\text { liquid water path } \\
\text { rain }\end{array}$ & $\begin{array}{l}\text { AMSU-A, } \\
\text { SSM/I, AMSR-E, } \\
\text { GPM (GMI) } \\
\text { MetOp-SG (MWS, MWI) }\end{array}$ \\
\hline $\begin{array}{l}\mathrm{V} \\
\mathrm{O}_{2}\end{array}$ & $\begin{array}{l}50.3,51.76, \\
52.8,53.75, \\
54.94,56.66, \\
58.00\end{array}$ & $0.2 / 0.5$ & $3.5^{\circ}$ & $\begin{array}{l}\text { temperature profile, } \\
\text { liquid water path, } \\
\text { precipitating } \\
\text { hydrometeors }\end{array}$ & $\begin{array}{l}\text { AMSU-A, } \\
\text { SSM/I(S) } \\
\text { MetOp-SG } \\
\text { (MWS, MWI) }\end{array}$ \\
\hline $\begin{array}{l}\text { W } \\
\text { window } \\
\text { channel }\end{array}$ & 90.0 & $0.25 / 1.5$ & $3.3^{\circ}$ & $\begin{array}{l}\text { liquid water path, } \\
\text { snow water path }\end{array}$ & $\begin{array}{l}\text { AMSU-B, } \\
\text { SSM/I(S), AMSR-E, } \\
\text { GPM (GMI) }\end{array}$ \\
\hline $\begin{array}{l}\mathrm{F} \\
\mathrm{O}_{2}\end{array}$ & $\begin{array}{l}118.75 \pm 8.5,118.75 \pm 4.2 \\
118.75 \pm 2.3,118.75 \pm 1.4\end{array}$ & $0.6 / 1.5$ & $3.3^{\circ}$ & $\begin{array}{l}\text { temperature profile } \\
\text { precipitating } \\
\text { hydrometeors }\end{array}$ & $\begin{array}{l}\text { MetOp-SG } \\
\text { (MWS, MWI) }\end{array}$ \\
\hline $\begin{array}{l}\mathrm{G} \\
\mathrm{H}_{2} \mathrm{O}\end{array}$ & $\begin{array}{l}183.31 \pm 12.5,183.31 \pm 7.5 \\
183.31 \pm 5.0,183.31 \pm 3.5 \\
183.31 \pm 2.5,183.31 \pm 1.5 \\
183.31 \pm 0.6\end{array}$ & $0.6 / 1.5$ & $2.7^{\circ}$ & $\begin{array}{l}\text { humidity profile } \\
\text { (upper troposphere), } \\
\text { ice water path }\end{array}$ & $\begin{array}{l}\text { AMSU-B, } \\
\text { SSM/I(S), } \\
\text { GPM (GMI) }\end{array}$ \\
\hline
\end{tabular}
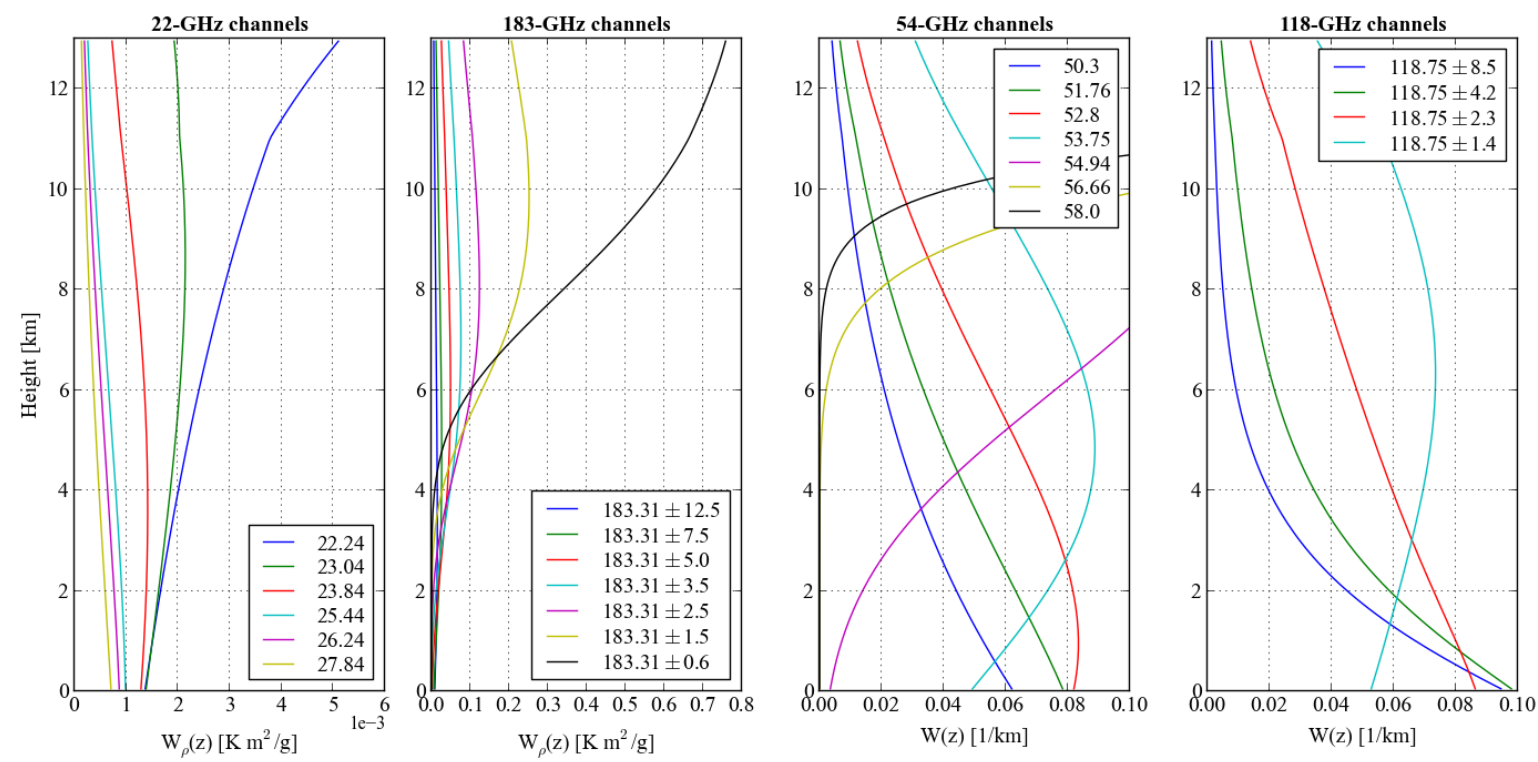

Figure 3. HAMP clear air weighting functions (nadir downward looking). Shown are the water vapor (two leftmost) and the temperature (two rightmost) weighting functions for a HALO ceiling height of about $13 \mathrm{~km}$. The US 1976 Standard Atmosphere over a black surface was assumed for the calculations.

The emission of liquid water increases roughly with the frequency squared. Window frequencies, such as the $90 \mathrm{GHz}$ W-band channel, together with channels correcting for water vapor influence ( $\mathrm{K}$ band) are therefore well suited to the detection of rain and cloud liquid. As explained above, the channels in both $\mathrm{O}_{2}$ bands have similar response to tempera- ture but differ in respect to their liquid water emission. These frequencies can be used for testing precipitation amount and profile retrievals applying the differential absorption method (Bauer and Mugnai, 2003). The potential advantage in comparison with classical window frequency retrievals is the robustness with respect to the unknown surface emissivity. 
19.09.2001 at $1800 \mathrm{UTC}$

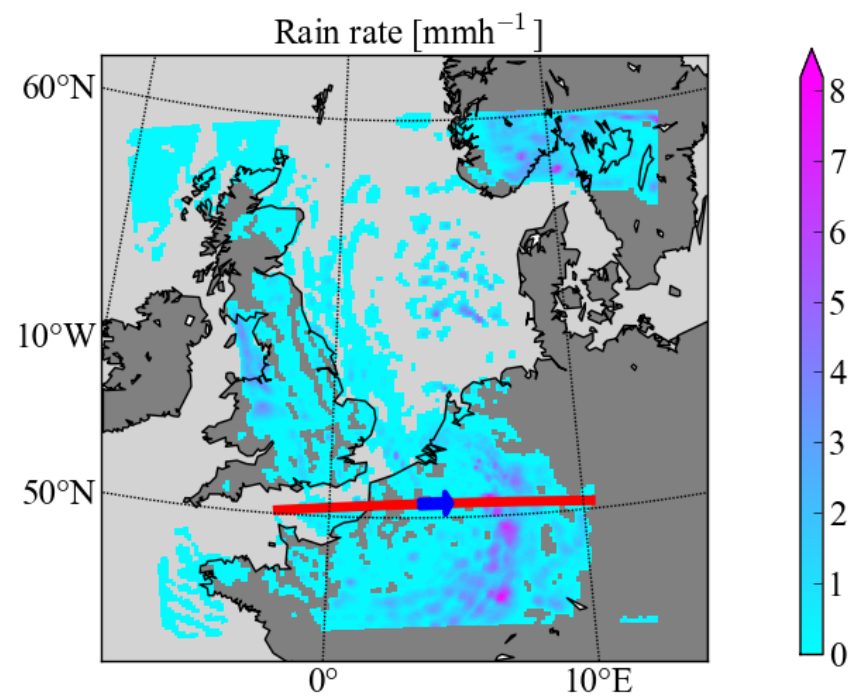

Figure 4. Simulated rain rates in $\mathrm{mm} \mathrm{h}^{-1}$ for the Hoek van Holland case on 19 September 2001 at 18:00 UTC. The red line and blue arrow indicate the artificial flight path shown in Figs. 5 and 6.

With increasing frequency, scattering by ice particles increases and higher window frequencies, i.e., the channels at

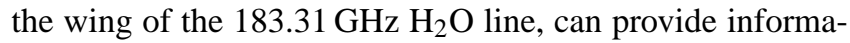
tion about snowfall. This illustrates the unique combination of HAMP channels that allows for the testing of various precipitation retrieval algorithms making mostly use of either the emission or the scattering signal.

\section{Simulations}

The synthetic observations in this study are based on calculations with the mesoscale nonhydrostatic model (MésoNH; Lafore et al., 1998). The cloud-resolving model provides the atmospheric state, including the mass mixing ratios of five hydrometeor categories (cloud water, cloud ice, rainwater, snow, and graupel) with a horizontal resolution of $10 \mathrm{~km}$ and 25 vertical levels. Five midlatitude precipitation events at two different times of cloud development have been selected, forming a set of more than 250000 profiles. The atmospheric scenarios and the cloud-resolving model setup is described in detail and compared to various satellite observations in Chaboureau et al. (2008). An example of the simulated rain rate for a precipitation event over Hoek van Holland on 19 September 2001 at 18:00 UTC is shown in Fig. 4.

To prepare the use of HAMP on HALO, synthetic observations have been created with the Passive and Active Microwave TRAnsfer model (PAMTRA), following the approach described in Mech et al. (2007). PAMTRA calculates fully polarized brightness temperatures for oriented particles, based on the radiative transfer model described in
Evans and Stephens (1995) and radar reflectivities following Smith (1984). Within PAMTRA, all assumptions concerning hydrometeor habits, their size distribution, and the method for the calculation of the single-scattering properties are consistent with cloud-resolving models used to generate the input data. For the present study, Méso-NH assumptions on hydrometeor size distribution have been used, and the single scattering properties for ice phase have been calculated using Mie theory and the soft sphere approximation with a fixed density of $0.2,0.4$, and $0.917 \mathrm{~g} \mathrm{~cm}^{-3}$ for snow, graupel, and cloud ice, respectively. Note that the typical assumption of spherical particles with fixed densities imposes significant TB uncertainties when larger amounts of frozen hydrometeors are present (Meirold-Mautner et al., 2007). The surface emissivity can be calculated using various methods: for ocean surfaces the FAST microwave Emissivity Model (FASTEM, version 4) is implemented (Liu et al., 2011); land surface emissivities are derived from monthly mean emissivity maps (Prigent et al., 1997) treated either as Lambertian or specular surfaces.

For each profile, brightness temperatures at the 26 passive frequencies ( 15 single sideband and 11 double sideband) considering the bandwidth and the radar reflectivities have been calculated. Together with the concurrent atmospheric state, these simulated observations form the database for the investigation on the performance and retrieval potential of HAMP.

In order to illustrate the sensitivity of HAMP measurements, a simulated flight through a precipitation event (Fig. 4) is analyzed. Figures 5 and 6 show the synthetic measurements, i.e., brightness temperatures and reflectivities, together with the corresponding hydrometeor contents. In general, the signal received by the passive microwave receivers of HAMP is, depending on channel, most strongly influenced by the total column content of hydrometeor amounts, the gaseous atmosphere, and/or the surface type, whereas the signal received at the radar is sensitive to the vertical distribution of the hydrometeor amounts.

In the brightness temperature simulations for the relatively transparent frequencies along the $22.24 \mathrm{GHz} \mathrm{H}_{2} \mathrm{O}$ line, the areas with high cloud and rainwater contents over ocean can be clearly seen as peaks of higher brightness temperature caused by high emission of the liquid hydrometeors (red arrow in Fig. 5). Over land, the emission of the liquid hydrometeor layers is covered to a large extent by the high emissivity of the land surfaces. The same holds true for the frequencies in the $60 \mathrm{GHz} \mathrm{O} \mathrm{O}_{2}$ complex. In comparison to the water vapor absorption around $22.24 \mathrm{GHz}$, the absorption through atmospheric oxygen is much stronger and the signal comes from higher atmospheric layers, so that the dynamic range of observable brightness temperatures decreases clearly when moving towards the center of the absorption complex. This effect is used for temperature profiling. Together with observations in the $\mathrm{O}_{2}$ band around $118.75 \mathrm{GHz}$, observations at the oxygen complex at $60 \mathrm{GHz}$ are proposed 


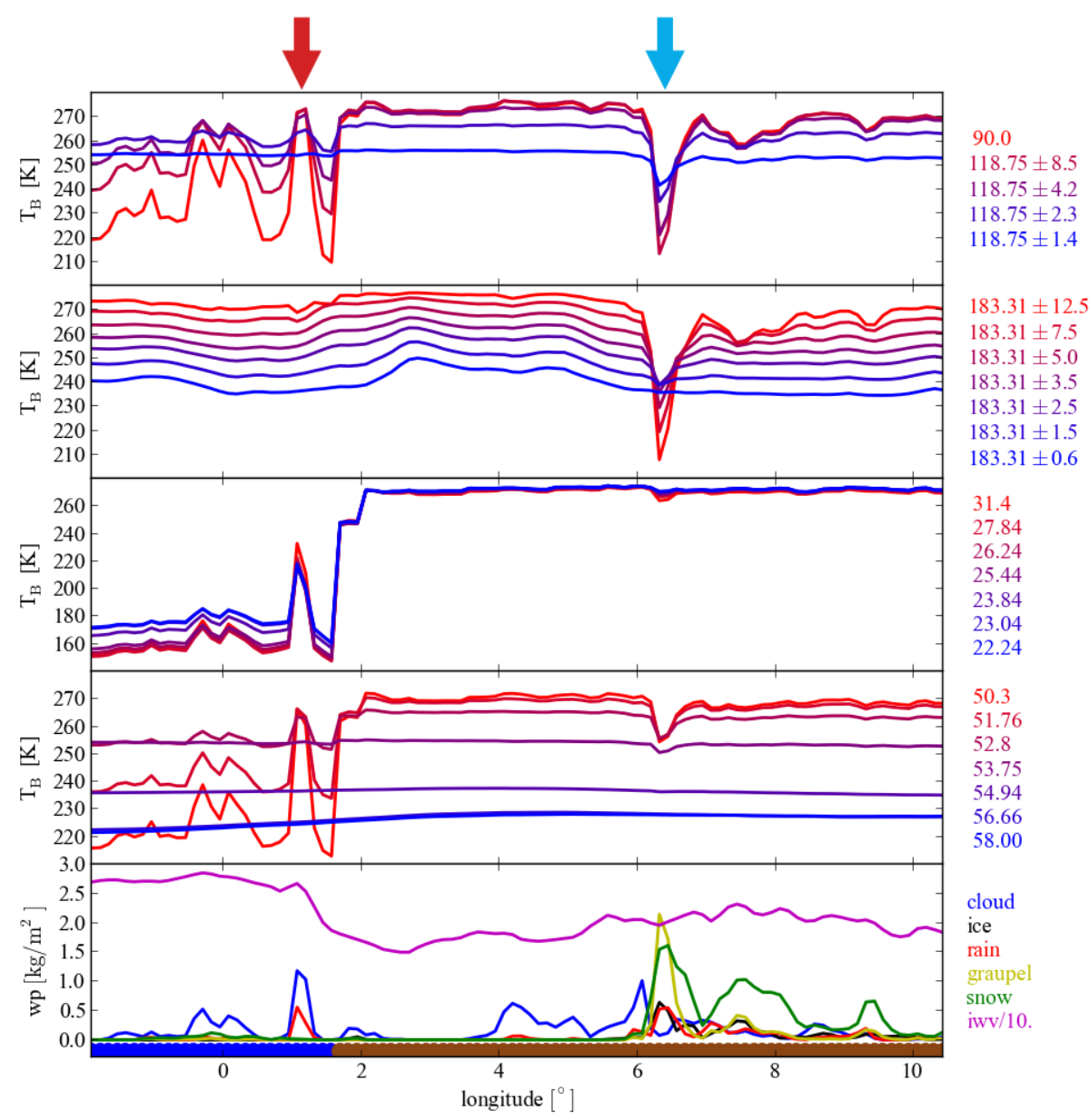

Figure 5. Integrated hydrometeor contents (bottom row) and simulated brightness temperatures along a cross section from west to east through a long-lasting precipitation event on 19 September 2001 at 18:00 UTC over Hoek van Holland (see Fig. 4). For a detailed description see text.

by Bauer and Mugnai (2003) for retrieval of precipitation and even of hydrometeor profiles by differential absorption (see Fig. 3). Thereby, combinations of frequencies at the wings of the complexes give information of the lower atmosphere, whereas frequencies towards the center are useful for the middle and upper troposphere.

The scattering effect of frozen hydrometeors over land (blue arrow in Fig. 5) can be clearly seen in the simulations for the higher HAMP frequencies at the wings of the $183.31 \mathrm{GHz} \mathrm{H}_{2} \mathrm{O}$ line. The relatively high total column contents of graupel and snow cause a brightness temperature depression of around $70 \mathrm{~K}$ at $183.31 \pm 12.5 \mathrm{GHz}$. Due to the atmospheric continuum absorption, frequencies above $150 \mathrm{GHz}$ are only slightly influenced or even completely uninfluenced by different surface emissivities for typical midlatitude conditions (Skofronick-Jackson and Johnson, 2011). Therefore, the scattering signal of graupel and snow can be seen over ocean surfaces as well (not shown in the example).

In Fig. 6 the simulated attenuated reflectivities for MIRA36 at $35.563 \mathrm{GHz}$, together with cross sections through the hydrometeor and water vapor fields, are shown along the track indicated in Fig. 4. It needs to be kept in mind that the coarse vertical resolution corresponds to the cloud-resolving model resolution and not to the range gates of the cloud radar. The high reflectivity values marked by the arrows are caused by rain (red and blue arrows), snow, and graupel (only blue arrow). The range of the hydrometeor contents and the attenuated reflectivities give an impression of the capabilities of the cloud radar on HAMP. Cloud ice leads to low reflectivities around $-35 \mathrm{dBZ}$, which is still in the sensitivity range of the radar, but would be missed by CloudSat.

\section{Retrieval potential}

Simulated brightness temperatures over ocean together with the concurrent atmospheric state and hydrometeor concentrations are used to test the retrieval potential of the HAMP radiometers. Multiple regression algorithms have been applied to retrieve temperature and humidity profiles. The equation 


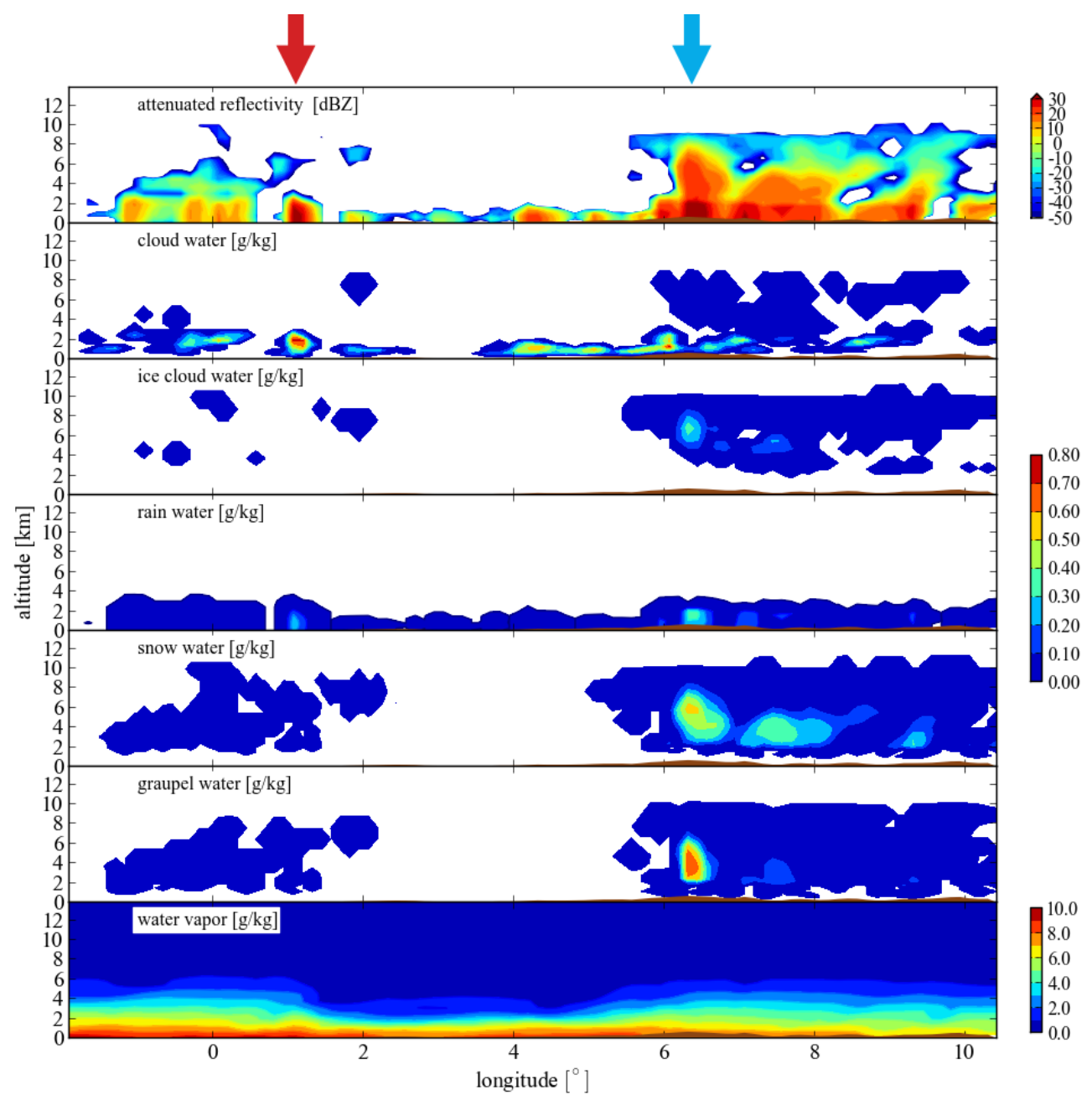

Figure 6. Attenuated reflectivities (top) and hydrometeor and water vapor contents along the same cross section as in Figs. 4 and 5.

relating the retrieved quantity and the brightness temperatures is

$q=a+\sum_{i=1}^{n_{\mathrm{tb}}} b_{i} \cdot T_{\mathrm{B}_{i}}+\sum_{i=1}^{n_{\mathrm{tb}}} c_{i} \cdot T_{\mathrm{B}_{i}}^{2}$

where $a, b_{i}$, and $c_{i}$ are the regression coefficients; $q$ the retrieved quantity for a specific atmospheric layer; and $T_{\mathrm{B}_{i}}$ the simulated brightness temperatures at nadir for $n_{\mathrm{tb}}$ frequencies, as the mean between horizontal and vertical polarization. By including quadratic terms, nonlinearities, like the saturation effect, can - at least partly - be taken into account. To develop the retrieval algorithm, the profiles in the database obtained from the Méso-NH simulations have been randomly divided into a training and a test data set. The training data set has been used to calculate regression coefficients. To assess the performance of the radiometers, the regression coefficients have been applied to the brightness temperatures derived by forward modeling from the test data set.

The retrieval approach is relatively simple and will be replaced with a Bayesian technique in the future. However, here we aim to assess the potential of the peculiar set of frequencies chosen for the HAMP radiometers in comparison to standard satellite instruments like AMSU-MHS for sounding of temperature and humidity profiles and SSM/I for precipitation, and want to avoid any influence from different a priori conditions or assumptions. Therefore, we use the same retrieval environment, viewing altitude, geometry (nadir only), and footprint size. The measurement uncertainty in the brightness temperatures has been taken into account by adding a random error to each of the channels following a Gaussian distribution. Two sets of retrieval coefficients have been calculated by adding different random errors to the simulated $T_{\mathrm{B}}$. The first one (annotated as 1 in Fig. 7) only considers the noise component expressed as NeDT, while the second one (annotated as 2 in Fig. 7) corresponds to the absolute accuracy, estimated by the vendor for HAMP (see Table 2) and reported in the Advanced TIROS (Television and Infrared Observational Satellite) Operational Vertical Sounder (ATOVS) manual (EUMETSAT, 2010) for AMSU-MHS. In addition to the root-mean-square 

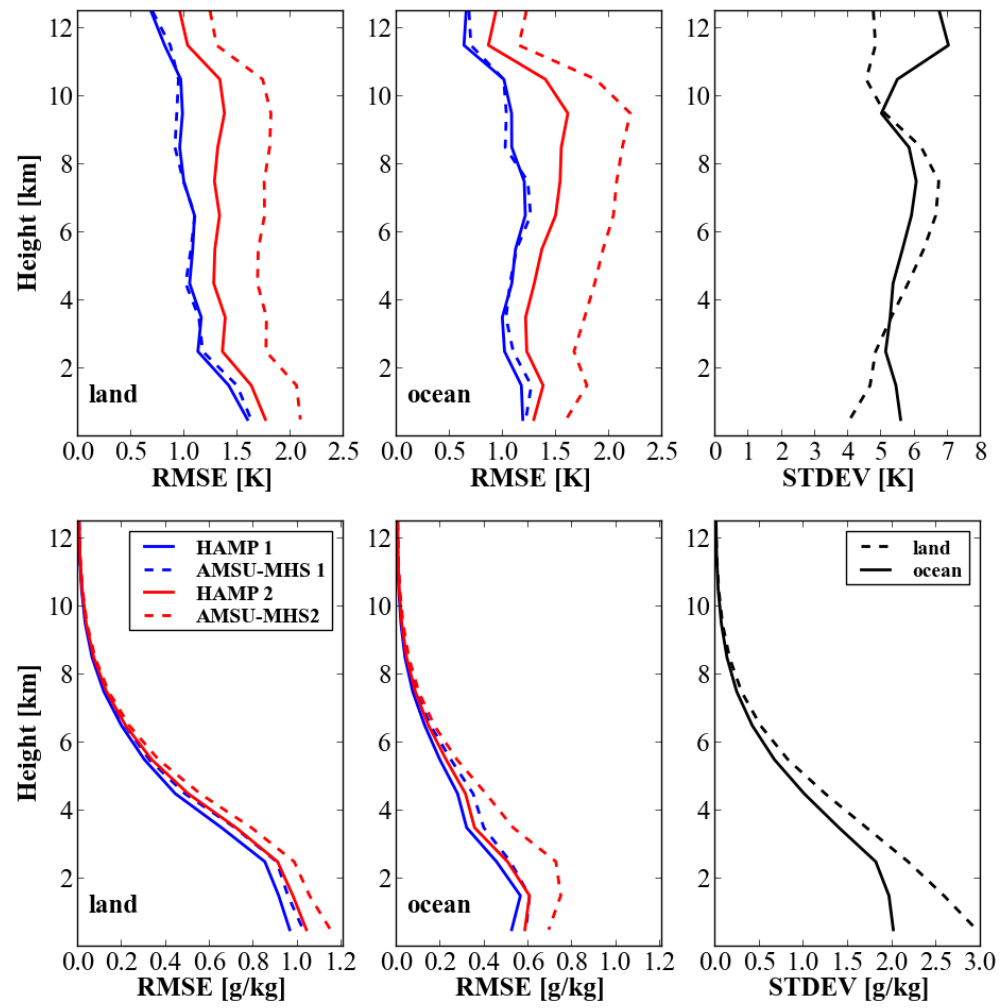

Figure 7. Retrieval RMSE over land (left), RMSE over ocean (middle), and test data set standard deviation (right) for temperature [K] (top panel) and water vapor mixing ratio $\left[\mathrm{g} \mathrm{kg}^{-1}\right.$ ] (bottom panels) for the HAMP (solid line) and AMSU-MHS (dashed line) instruments with two different assumptions on $T_{\mathrm{B}}$ uncertainty. See text for details.

error (RMSE) of the retrieved $T$ and $q$ profile, Fig. 7 also shows the standard deviation of the test data to give a measure of the improvement achieved via the retrieval algorithm with respect to the climatological variability.

The uncertainty of the retrieved temperature profiles varies between 0.6 and $2.2 \mathrm{~K}$ (Fig. 7). Close to the simulated aircraft flying altitude $(13 \mathrm{~km})$, the $T$ retrieval has the smallest error over the profile, i.e., $0.6 \mathrm{~K}$. This is due to the decrease in measurement standard deviation and to the shape of the weighting function of the two opaque channels at 58 and $56.66 \mathrm{GHz}$ (Fig. 3), which contain information of the temperature profile of the atmospheric layers close to the radiometer. The RMSE for $T$ is strongly dependent on the assumed $T_{\mathrm{B}}$ uncertainty, with highest RMSE of $2.2 \mathrm{~K}$ for the AMSU-MHS instrument at $9.5 \mathrm{~km}$ height. Considering the pure noise $T_{\mathrm{B}}$ uncertainty (1) for both instruments, it can be noted that HAMP has smaller retrieval errors in the lowest $3-4 \mathrm{~km}$ of the troposphere (blue lines in Fig. 7). This is due to its large number of temperature sounding channels with weighting function peaking at ground (see Fig. 3), i.e., the $119 \mathrm{GHz}$ receiver is not implemented in AMSU-MHS.

Concerning water vapor, the RMSE over ocean is smaller than over land and so is the ratio between retrieval RMSE and the standard deviation of the test data set. The better retrieval accuracy over ocean is due to the strong contrast between the radiation emitted by water vapor and the radiatively cold ocean. Due to the higher number of channels within water vapor absorption lines, HAMP has smaller RMSE than AMSU-MHS for the water vapor mixing ratio retrieval from the ground up to $2 \mathrm{~km}$, with both possible assumptions on the $T_{\mathrm{B}}$ uncertainty. $T$ and $q$ error profiles found in this work are similar to those found by Aires et al. (2011), where a synthetic database of $T_{\mathrm{B}}$ and a linear regression algorithm was used. Nevertheless, a direct comparison cannot be made due to the differences in the simulated database and the viewing altitude.

A multiple regression algorithm has also been developed for precipitation using HAMP and SSM/I frequencies, taking into account the different viewing geometries and polarizations, and using the same viewing altitude $(13 \mathrm{~km})$ and footprint size. Results (see supplementary material) show that the RMSEs for retrieval with HAMP range from $60 \%$ at $1 \mathrm{mmh}^{-1}$ to $25 \%$ at $10 \mathrm{mmh}^{-1}, 5$ to $12 \%$ better than retrievals with the SSM/I instrument. HAMP's capability of retrieving precipitation is comparable to the one reported in Defer et al. (2008) for the AMSU-MHS instrument. 


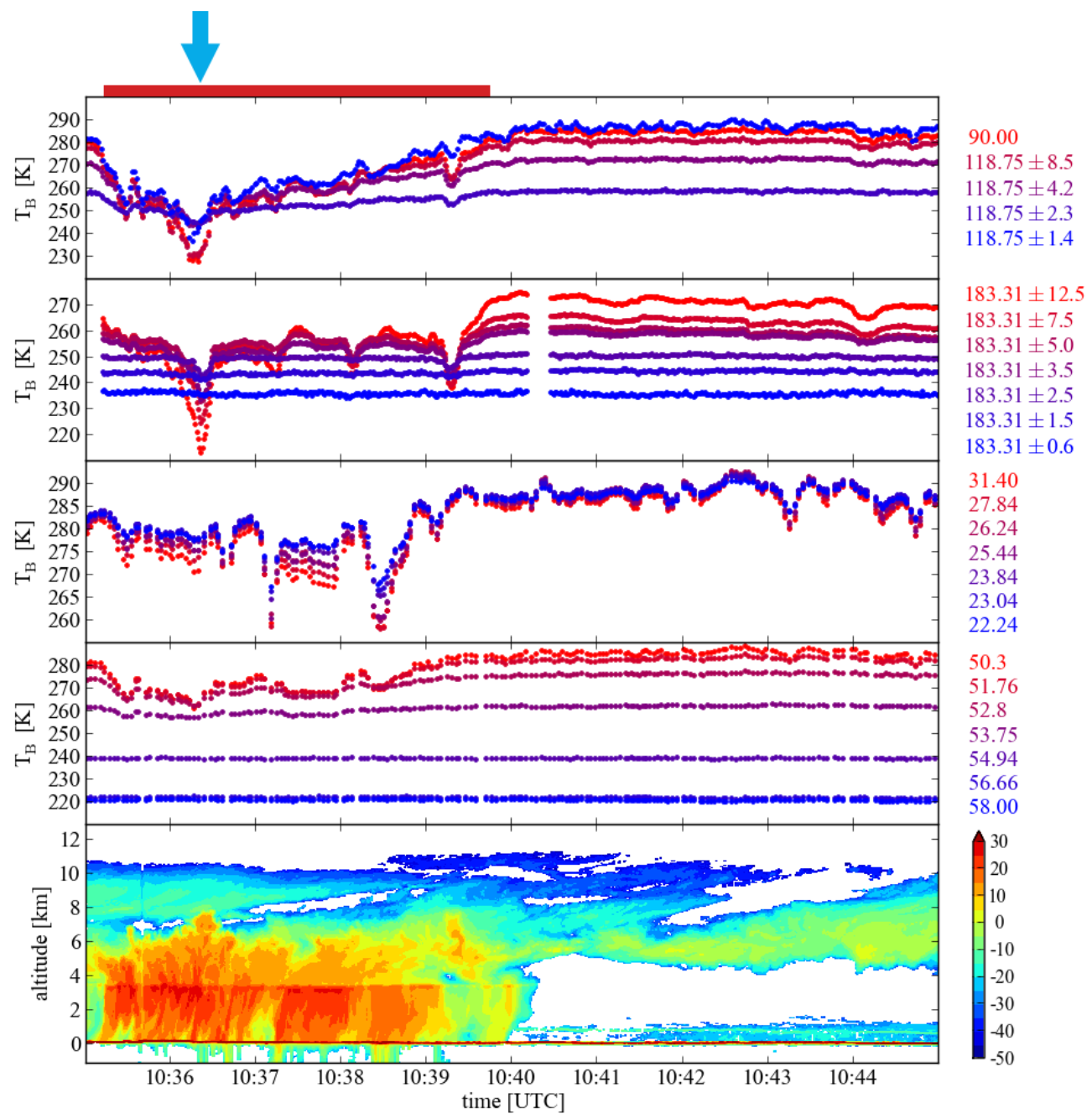

Figure 8. Measurements taken by HAMP on 24 July 2013 over western Germany. The upper four panels show the measurements taken by the radiometer modules. The lower panel shows the reflectivities in dBZ captured by the MIRA-36 cloud radar.

\section{Electromagnetic compatibility and demonstration flights}

To achieve flight permission with the remote sensing and auxiliary instrumentation onboard HALO and to test their performance, one electromagnetic compatibility and two scientific demonstration (or demo) flights were performed. Thirteen flight hours with the full equipment planned for the NARVAL campaign were conducted over the course of three flights in the summer of 2013. These flights were also used to test the setup, calibration, in-flight operation, and performance of HAMP on HALO. The instruments were operated successfully on all three flights and, apart from short periods for testing different instrument parameters, HAMP was continuously measuring.

Figure 8 shows 10 min of measurements taken by the HAMP instruments on the third demo flight, which took place on 24 July 2013 at a flight level of $13 \mathrm{~km}$. The $10 \mathrm{~min}$ period corresponds to the passage over convective and precipitating clouds over western Germany. In general, similar signals can be seen in the measurements (Fig. 8) as were evident in the simulations of the instruments (Figs. 5 and 6), i.e., emission signals in the lower bands due to clouds and precipitation (red bar), scattering in higher window bands due to frozen hydrometeors (blue arrow), and high re ectivities in the precipitating regions.

In the lower panel of Fig. 8, the equivalent reflectivity signal $(\mathrm{Ze})$ received by the radar is shown. With focus initially on the first $5 \mathrm{~min}$, the high reflectivity values $(>20 \mathrm{~dB})$ below $3.5 \mathrm{~km}$ height are indicative of rain. Somewhat smaller reflectivities above $3.5 \mathrm{~km}$ are from precipitation in the ice phase or, in the case of very low reflectivities, ice clouds. The transition from ice to rain can be seen by the melting layer (bright band), a layer of enhanced reflectivity and the sharp vertical gradient in Ze near $3.5 \mathrm{~km}$. The Ze values below $0 \mathrm{~m}$ height are due to multiple scattering. This mirror im- 
age gives the possibility to retrieve surface precipitation rate (Li and Nakamura, 2002). The second half of the presented data shows mid- to high-level clouds with signals around $5 \mathrm{~dB}$ at $5.5 \mathrm{~km}$ and the echo of the Earth surface at about $0 \mathrm{~km}$ altitude and clear-air echoes (probably insects) in the boundary layer up to $1.3 \mathrm{~km}$ altitude.

The measurements taken by the radiometers in the five different frequency bands are shown in the upper four panels of Fig. 8. As described in Sect. 3, the brightness temperatures received at the passive radiometers are composed of signals from gaseous atmosphere, precipitation, clouds, and the surface. Due to the higher surface emissivity over land, the presence of clouds and precipitation can be seen by depressed brightness temperatures in the lower bands in contrast to the cloud and precipitation signal over ocean. The stronger surface signal dominates in these channels in the second part of the flight section, where no liquid hydrometeors are present. The depression in the higher window frequencies is caused by the superimposition of the emission signal by liquid hydrometeors and the scattering at the ice phase. Both effects contribute to the decrease in the brightness temperature with respect to clear-sky situations over land. Scattering by large snow particles is likely responsible for the drop by more than $30 \mathrm{~K}$ at around 10:36 UTC (blue arrow), where strong reflectivities can be observed above the bright band in the radar signal. Albeit smaller, a similar signal can be seen at 10:39 UTC. Thinner clouds with a lower liquid or ice water content show smaller depressions in the brightness temperature. Channels closer to the center of absorption complexes or lines at $58 \mathrm{GHz}$ for oxygen or $183 \mathrm{GHz}$ for water vapor are more opaque and are strongly influenced by the gaseous atmosphere. Their peak in the weighting function (Fig. 3) is often above the clouds. Therefore, the brightness temperature received is more stable during the period and gives an indication of the temperature or humidity at the height of the weighting function peak.

The gap at 10:41 UTC in the $183 \mathrm{GHz}$ band is due to calibration. Since the calibration is performed in a different way for the other bands, they do not show such gaps.

\section{Conclusions}

A novel suite of microwave remote sensing instrumentation, the HALO Microwave Package (HAMP), has been developed for use by the new High-Altitude and LOng-range research aircraft (HALO). This instrumentation is comprised of a nadir-pointing polarized cloud radar operating at $35.5 \mathrm{GHz}$, and three modules of nadir-pointing radiometers operating over 26 frequencies in five bands. The instrumentation, combined with the capabilities of the HALO aircraft, provides a unique remote sensing platform for use in characterizing the state of water in all its phases, as well as temperature, through the depth of the troposphere.
Simulations using a radiative transfer code and synthetic data as well as in-flight testing of HAMP give a good impression of the capabilities that these measurements have for studies of the atmosphere's most important constituent, water. The multifrequency passive microwave measurements are sensitive to the various hydrometeor types, their integrated contents, atmospheric water vapor and temperature distribution, and surface properties. Measurements by the $35.563 \mathrm{GHz}$ cloud radar will provide information about the vertical distribution of hydrometeors. Therefore, by the combination of active and passive components on HAMP, the complete vertical structure of the troposphere with respect to parameters of the water cycle and the temperature can be obtained.

To prepare the use of HAMP on HALO, synthetic observations have been created with the help of radiative transfer calculations. Simulated brightness temperatures have been used to evaluate the performance of the HAMP radiometers given common retrieval algorithms as used by satellite remote sensing. Due to the inclusion of frequencies spanning from 22.24 to $183.31 \pm 12.5 \mathrm{GHz}$, HAMP radiometers showed promising capabilities for the retrieval of temperature and humidity profiles over the ocean. Regarding profiling potential, HAMP showed better performance than AMSU-MHS for humidity and temperature in the lower atmosphere.

During $13 \mathrm{~h}$ of test flights, measurements have been performed which demonstrate that the instruments performed stably, and with the expected performance characteristics.

The capabilities of HAMP, and its sister instruments consisting of a water vapor lidar and a dropsonde system, formed the basis for the Next-generation Aircraft Remote sensing for VALidation studies (NARVAL) campaign. NARVAL, whose focus was on the characterization of precipitation from relatively shallow clouds, took place in December 2013 and January 2014. In the December phase of NARVAL, shallow convection and its covariability with atmospheric water across the breadth of the North Atlantic trade winds was measured over the course of eight research flights. These measurements serve as a way to evaluate the representativeness of longterm measurements at the Barbados Cloud Observatory to the broader trade winds (Nuijens et al., 2014). During the January phase of NARVAL, frequently occurring intensive post-frontal mesoscale precipitation was observed over the North Atlantic near Iceland. For one thing, these systems are thought to play a critical role in the water cycle, and for another the development of midlatitude storm systems, but are poorly measured by other platforms. During NARVAL the HAMP instrumentation operated with almost no interruption over more than 150 flight hours, and initial analyses suggest that the instrumentation lived up to the promise of the analyses presented in this paper. In so doing, HAMP promises to open a new dimension to atmospheric remote sensing. 


\section{The Supplement related to this article is available online at doi:10.5194/amt-7-4539-2014-supplement.}

Acknowledgements. This research was supported by the German Science Foundation (DFG), within the the priority program "High Altitude and Long Range Research Aircraft (HALO)" SPP 1294 under grants AM 308/4-1 and CR 111/9-1.

Edited by: D. Feist

\section{References}

Aires, F., Paul, M., Prigent, C., Rommen, B., and Bouvet, M.: Measure and exploitation of multisensor and multiwavelength synergy for remote sensing: 2. Application to the retrieval of atmospheric temperature and water vapor from MetOp, J. Geophys. Res., 116, D02302, doi:10.1029/2010JD014702, 2011.

Allan, R. P., Soden, B. J., John, V. O., Ingram, W., and Good, P.: Current changes in tropical precipitation, Environ. Res. Lett., 5, 025205, doi:10.1088/1748-9326/5/2/025205, 2010.

Andersson, A., Fennig, K., Klepp, C., Bakan, S., Graß1, H., and Schulz, J.: The Hamburg Ocean Atmosphere Parameters and fluxes from satellite data - HOAPS-3, Earth Syst. Sci. Data, 2, 215-234, doi:10.5194/essd-2-215-2010, 2010.

Barker, H., Korolev, A., Hudak, D., Strapp, J., Strawbridge, K., and Wolde, M.: A comparison between CloudSat and aircraft data for a multilayer, mixed phase cloud system during the Canadian CloudSat-CALIPSO validation project, J. Geophys. Res., 113, D00A16, doi:10.1029/2008JD009971, 2008.

Bauer, P. and Mugnai, A.: Precipitation profile retrievals using temperature-sounding microwave observations, J. Geophys. Res., 108, doi:10.1029/2003JD003572, 2003.

Bauer, P., Amayenc, P., Kummerow, C. D., and Smith, E. A.: Overocean rainfall retrieval from multisensor data of the Tropical Rainfall Measuring Mission. Part II: Algorithm implementation, J. Atmos. Ocean. Tech., 18, 1838-1855, 2001.

Berg, W., L'Ecuyer, T., and Haynes, J. M.: The distribution of rainfall over oceans from spaceborne radars, J. Appl. Meteorol. Clim., 49, 535-543, 2010.

Bidwell, S. W., Flaming, G. M., Durning, J. F., and Smith, E. A.: The Global Precipitation Measurement (GPM) Microwave Imager (GMI) instrument: Role, performance, and status, in: Geoscience and RemoteSensing Symposium, IGARSS'05, Proceedings, Vol. 10, IEEE International, Seoul, p. 4, 2005.

Blackwell, W. J., Barrett, J. W., Chen, F. W., Leslie, R. V., Rosenkranz, P. W., Schwartz, M. J., and Staelin, D. H.: NPOESS Aircraft Sounder Testbed-Microwave (NAST-M): instrument description and initial flight results, IEEE T. Geosci. Remote, 39, 2244-2253, 2001.

Braun, S. A., Kakar, R., Zipser, E., Heymsfield, G., Albers, C., Brown, S., Durden, S. L., Guimond, S., Halverson, J., Heymsfield, A., Lambrigtsen, B., Miller, T., Tanelli, S., Janel, T., and Zawislak, J.: NASA's Genesis and Rapid Intensification Processes (GRIP) field experiment, B. Am. Meteorol. Soc., 94, 345$363,2013$.
Brown, S., Lambrigtsen, B., Denning, R., Gaier, T., Kangaslahti, P., Lim, B., Tanabe, J., and Tanner, A.: The High-Altitude MMIC sounding radiometer for the Global Hawk unmanned aerial vehicle: instrument description and performance, IEEE T. Geosci. Remote, 49, 3291-3301, 2011.

Chaboureau, J.-P., Söhne, N., Pinty, J.-P., Meirold-Mautner, I., Defer, E., Prigent, C., Pardo, J., Mech, M., and Crewell, S.: A midlatitude cloud database validated with satellite observations, J. Appl. Meteorol., 47, 1337-1353, 2008.

Defer, E., Prigent, C., Aires, F., Pardo, J. R., Walden, C. J., Zanifé, O.-Z., Chaboureau, J.-P., and Pinty, J.-P.: Development of precipitation retrievals at millimeter and submillimeter wavelengths for geostationary satellites, J. Geophys. Res., 113, D08111, doi:10.1029/2007JD008673, 2008.

EUMETSAT: ATOVS Level $1 \mathrm{~b}$ Product Guide, EUMETSAT, available at: http://oiswww.eumetsat.org/WEBOPS/ eps-pg/ATOVS-L1/ATOVSL1-PG-0TOC.htm (last access: 6 May 2014), 2010.

Evans, K. F. and Stephens, G. L.: Microwave radiative transfer through clouds composed of realistically shaped ice crystals, Part I: Single scattering properties, J. Atmos. Sci., 52, 2041-2057, 1995.

Evans, K. F., Wang, J. R., Racette, P. E., Heymsfield, G., and Li, L.: Ice cloud retrievals and analysis with the Compact Scanning Submillimeter Imaging Radiometer and the cloud radar system during CRYSTAL-FACE, J. Appl. Meteorol., 44, 839-859, 2005.

Geerts, B., Heymsfield, G. M., Tian, L., Halverson, J. B., Guillory, A., and Mejia, M. I.: Hurricane Georges's landfall in the Dominican Republic: detailed airborne Doppler radar imagery, B. Am. Meteorol. Soc., 81, 999-1018, 2000.

Halverson, J., Black, M., Rogers, R., Braun, S., Heymsfield, G., Cecil, D., Goodman, M., Hood, R., Heymsfield, A., Krishnamurti, T., McFarquhar, G., Mahoney, M. J., Molinari, J., Turk, J., Velden, C., Zhang, D.-L., Zipser, E., and Kakar, R.: Nasa's Tropical Cloud Systems and Processes Experiment, B. Am. Meteorol. Soc., 88, 867-882, doi:10.1175/BAMS-88-6-867, 2007.

Hock, T. and Franklin, J.: The NCAR GPS dropwindsonde, B. Am. Meteorol. Soc., 80, 407-420, 1999.

Hou, A. Y., Kakar, R. K., Neeck, S., Azarbarzin, A. A., Kummerow, C. D., Kojima, M., Oki, R., Nakamura, K., and Iguchi, T.: The Global Precipitation Measurement (GPM) mission, B. Am. Meteorol. Soc., doi:10.1175/BAMS-D-13-00164.1, online first, 2013.

Kidd, C. and Huffman, G.: Global precipitation measurement, Meteorol. Appl., 18, 334-353, 2011.

Kidder, S., Goldberg, M., Zehr, R., DeMaria, M., Purdom, J., Velden, C., Grody, N., and Kusselson, S.: Satellite analysis of tropical cyclones using the Advanced Microwave Sounding Unit (AMSU), B. Am. Meteorol. Soc., 81, 1241-1260, 2000.

Klepp, C. P., Bakan, S., and Graßl, H.: Improvements of satellitederived cyclonic rainfall over the North Atlantic, J. Climate, 16, 657-669, 2003.

Lafore, J. P., Stein, J., Asencio, N., Bougeault, P., Ducrocq, V., Duron, J., Fischer, C., Héreil, P., Mascart, P., Masson, V., Pinty, J. P., Redelsperger, J. L., Richard, E., and VilàGuerau de Arellano, J.: The Meso-NH Atmospheric Simulation System. Part I: adiabatic formulation and control simulations, Ann. Geophys., 16, 90-109, doi:10.1007/s00585-997-0090-6, 1998. 
Lee, W.-C., Dodge, P., Marks, F. D., and Hildebrand, P. H.: Mapping of Airborne Doppler Radar Data, J. Atmos. Ocean. Tech., 11, 572-578, 1994.

Li, J. and Nakamura, K.: Characteristics of the mirror image of precipitation observed by the TRMM precipitation radar, J. Atmos. Ocean. Tech., 19, 145-158, 2002.

Li, L., Heymsfield, G. M., Racette, P. E., Tian, L., and Zenker, E.: A $94 \mathrm{GHz}$ Cloud Radar System on a NASA High-altitude ER-2 Aircraft, J. Atmos. Ocean. Tech., 21, 1378-1388, 2003.

Li, L., Heymsfield, G., Carswell, J. R., Schaubert, D., Creticos, J., and Vega, M.: High-Altitude Imaging Wind and Rain Airborne Radar (HIWRAP), in: IGARSS, IEEE International, 3, Boston, MA, 7-11 July 2008, 354-357, 2008.

Liu, Q., Weng, F., and English, S. J.: An improved fast microwave water emissivity model, IEEE T. Geosci. Remote, 49, 12381250, 2011

Lobl, S. E., Aonashi, K., Griffith, B., Kummerow, C., Liu, G., Murakami, M., and Wilheit, T.: Wakasa Bay: an AMSR precipitation validation campaign, B. Am. Meteorol. Soc., 88, 551-558, 2007.

Mech, M., Crewell, S., Meirold-Mautner, I., Prigent, C., and Chaboureau, J.-P.: Information content of millimeter-wave observations for hydrometeor properties in mid-latitudes, IEEE T. Geosci. Remote, 45, 2287-2299, 2007.

Meirold-Mautner, I., Prigent, C., Pardo, J. R., Chaboureau, J.-P., Pinty, J.-P., Mech, M., and Crewell, S.: Radiative transfer simulations using mesoscale cloud model outputs and comparisons with passive microwave and infrared satellite observations for mid-latitude situations, J. Atmos. Sci., 64, 1550-1568, 2007.

Melchionna, S., Bauer, M., and Peters, G.: A new algorithm for the extraction of cloud parameters using multipeak analysis of cloud radar data - first application and preliminary results, Meteorol. Z., 17, 613-620, 2008.

NASDA: TRMM PR Algorithm Instruction Manual V1.0. Communications Research Laborator, 4-2-1 Nukui-kitamachi, Koganeichi, Tokyo 184, Japan, 1999.

Norenberg, D., Crewell, S., Lohnert, U., Rose, T., and Martellucci, A.: A Novel Ground-Based Microwave Radiometer for High Precision Atmospheric Observations between 10 and 90 GHz, in: Geoscience and Remote Sensing Symposium, 2008. IGARSS 2008. IEEE International, vol. 3, III - 919-III - 922, doi:10.1109/IGARSS.2008.4779500, 2008.

Nuijens, L., Stevens, B., and SIEBESMA, A. P.: The environment of precipitating shallow cumulus convection, J. Atmos. Sci., 66, 1962-1979, 2009.

Nuijens, L., Serikov, I., Hirsch, L., Lonitz, K., and Stevens, B.: The distribution and variability of low-level cloud in the NorthAtlantic trades, Q. J. Roy. Meteor. Soc., doi:10.1002/qj.2307, online first, 2014.

O’Dell, C. W., Wentz, F. J., and Bennartz, R.: Cloud liquid water path from satellite-based passive microwave observations: a new climatology over the global oceans, J. Climate, 21, 1721-1739, 2008.

Pelon, J., Vali, G., Ancellet, G., Ehret, G., Flamant, P. H., Haimov, S., Heymsfield, G., Leon, D., Mead, J. B., Pazmany, A. L., Protat, A., Wang, Z., and Wolde, M.: LIDAR and RADAR observations, in: Airborne Measurements for Environmental Research: Methods and Instruments, edited by: Wendisch, M. and Brenguier, J.-L., Wiley-VCH Verlag GmbH \& Co. KGaA, Weinheim, Germany, 2013.
Prigent, C., Rossow, W. B., and Matthews, E.: Microwave land surface emissivities estimated from SSM/I observations, J. Geophys. Res., 102, 21867-21890, 1997.

Rose, T., Crewell, S., Löhnert, U., and Simmer, C.: A network suitable microwave radiometer for operational monitoring of the cloudy atmosphere, Atmos. Res., 75, 183-200, 2005.

Skofronick-Jackson, G. and Johnson, B. T.: Surface and atmospheric contributions to passive microwave brightness temperatures for falling snow events, J. Geophys. Res., 116, D02213, doi:10.1029/2010JD014438, 2011.

Skofronick-Jackson, G. M., Wang, J. R., Heymsfield, G. M., Hood, R., Manning, W., Menighini, R., and Weinman, J. A.: Combined radiometer-radar microphysical profile estimations with emphasis on high-frequency brightness temperature observations, J. Appl. Meteorol., 42, 476-487, 2003.

Smith, P. L.: Equivalent radar reflectivity factors for snow and ice particles, J. Clim. Appl. Meteorol., 23, 1258-1260, 1984.

Stephens, G. L., Vane, D. G., Boain, R. J., Mace, G. G., Sassen, K., Wang, Z., Illingworth, A. J., O'Connor, E. J., Rossow, W. B., Durden, S. L., Miller, S. D., Austin, R. T., Benedetti, A., Mitrescu, C., and the CloudSat Science Team: The CloudSat mission and the A-TRAIN: a new dimension to space-based observations of clouds and precipitation, B. Am. Meteorol. Soc., 83, 1771-1790, 2002.

Stephens, G. L., Li, J., Wild, M., Clayson, C. A., Loeb, N., Kato, S., L'Ecuyer, T., Stackhouse Jr, P. W., Lebsock, M., and Andrews, T. An update on Earth's energy balance in light of the latest global observations, Nat. Geosci., 5, 691-696, doi:10.1038/ngeo1580, 2012.

Stevens, B. and Bony, S.: Water in the atmosphere, Phys. Today, 66, 29-34, 2013a.

Stevens, B. and Bony, S.: What are climate models missing, Science, 340, 1053-1054, 2013b.

Toon, O. B., Starr, D. O., Jensen, E. J., Newman, P. A., Platnick, S., Schoeberl, M. R., Wennberg, P. O., Wofsy, S. C., Kurylo, M. J., Maring, H., Jucks, K. W., Craig, M. S., Vasques, M. F., Pfister, L., Rosenlof, K. H., Selkirk, H. B., Colarco, P. R., Kawa, S. R., Mace, G. G., Minnis, P., and Pickering, K. E.: Planning, implementation, and first results of the Tropical Composition, Cloud and Climate Coupling Experiment (TC4), J. Geophys. Res.-Atmos., 115, D00J04, doi:10.1029/2009JD013073, 2010.

Tortora, P., Crewell, S., Elgered, G., Graziani, A., Jarlemark, P., Löhnert, U., Martellucci, A., Mercolino, M., Rose, T., and Schween, J. H.: AWARDS: Advanced microwave radiometers for deep space stations., Space Communications, 22, 159-170, 2013.

von Bremen, L., Ruprecht, E., and Macke, A.: Errors in liquid water path retrieval arising from cloud inhomogeneities: the beamfilling effect, Meteorol. Z., 11, 13-19, 2002.

Wang, J.-J., Adler, R. F., Huffman, G. J., and Bolvin, D.: An updated TRMM composite climatology of tropical rainfall and its validation, J. Climate, 27, 273-284, 2013.

Wang, J. R., Racette, P. E., Piepmeier, J. R., and Monosmith, B.: Airborne CoSMIR observations between 50 and $183 \mathrm{GHz}$ over snow-covered Sierra Mountains, IEEE T. Geosci. Remote, 45, 55-61, 2007.

Wang, J. R., Racette, P. E., and Piepmeier, J. R.: A comparison of near-concurrent measurements from the SSMIS and CoSMIR for 
some selected channels over the frequency range of $50-183 \mathrm{GHz}$, IEEE T. Geosci. Remote, 46, 923-933, 2008.

Wendisch, M., Pilewskie, P., Bohn, B., Bucholtz, A., Crewell, S., Harlow, C., Jäkel, E., Schmidt, K. S., Shetter, R., Taylor, J., Turner, D. D., and Zöger, M.: Atmospheric radiation measurements, in: Airborne Measurements for Environmental Research: Methods and Instruments, edited by: Wendisch, M. and Brenguier, J.-L., Ch. Atmospheric Radiation Measurements, 343411, Wiley-VCH Verlag GmbH \& Co. KGaA, Weinheim, Germany, 2013.
Wirth, M., Fix, A., Mahnke, P., Schwarzer, H., Schrandt, F., and Ehret, G.: The airborne multi-wavelength water vapor differential absorption lidar WALES: system design and performance, Appl. Phys. B, 96, 201-213, 2009.

Ziereis, H. and Gläßer, M.: Global Player für die Atmosphärenforschung - HALO, DLR-Magazin, 115, 32-36, 2006. 